\title{
MUTACIÓN BIOLÓGICA Y VANGUARDIAS LITERARIAS
}

\author{
Hugues MARCHAL \\ Universidad de Basilea \\ hugues.marchal@unibas.ch
}

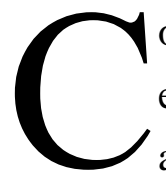

on la teorización, en el umbral del siglo XX, del concepto biológico de mutación, la naturaleza, esa garante de estabilidad durante mucho tiempo oponible a las tentativas de evolución artística radical, traicionó el campo de los «clásicos»: ir en contra de las formas heredadas, consideradas imitadoras del orden del mundo, demostró ser la mejor imitación de dicho orden. El fenómeno biológico proporcionó así a los creadores más innovadores o iconoclastas un argumento para defender sus infracciones a los códigos vigentes, mediante un diálogo entre ciencias y experimentación estética, algunas de cuyas etapas se indicarán aquí.

\section{Una evolución sin mutación}

Entre 1850 y 1900, si la historia natural sirve de marco para pensar la evolución de las formas literarias, esta utilización tiende paradójicamente a hacer un alegato en favor de la estabilidad de dichas formas.

Taine postula una relación entre la creación artística y un substrato fisiológico profundo: la cultura refleja el impacto del medio y del momento sobre una raza, término definido como «esas disposiciones innatas y hereditarias que el hombre saca consigo a la luz y que ordinariamente se vinculan a diferencias marcadas en el temperamento y en la estructura del cuerpo» (1866: XXIII). Elementos fundadores de cada gran tradición, «estas aptitudes y esos instintos se encuentran en la sangre»; «para alterarlos se precisa [...] una transformación del temperamento y de la estructura corporal» (1867: 41). Ahora bien, dicha transformación fisiológica ocurre fuera del tiempo humano: «aunque la inmensidad de la distancia solo nos deja entrever a medias y bajo una luz dudosa el origen de las especies, los acontecimientos de la historia iluminan suficientemente los acontecimientos anteriores a la historia, para explicar la solidez casi inquebrantable de los caracteres primordiales» (1866: XXIV-XXV). Las posibilidades de desvío que se ofrecen a la creación se hallan pues limitadas por la invariancia relativa de su base biológica, igual que se le suma el patrimonio cultural como otra forma de herencia. La historia de cada pueblo recae en el presente con «un peso desproporcionado al 
resto y casi imposible de levantar, ya que cada minuto de un pasado casi infinito ha contribuido a sobrecargarlo» (XXVI). Treinta años más tarde, Brunetière aplica a las propias especies literarias el modelo de evolución de las especies. La aparición de nuevos géneros plantea una cuestión «análoga a la de saber cómo, en la historia natural, de un mismo principio de ser y de substancia, común y homogéneo, los individuos se despegan con sus formas particulares, convirtiéndose así en el tronco sucesivo de variedades, de razas, de especies» (1890: 11). La respuesta es similar: «la diferenciación de los géneros opera, en la historia, como la de las especies en la naturaleza, progresivamente, por transición del uno al múltiplo, de lo simple a lo complejo, de lo homogéneo a lo heterogéneo, gracias al llamando principio de divergencia de caracteres» (20). Las reglas de la competición vital someten las variaciones a una selección, por la que las especies estéticas más aptas se imponen. Pero como Darwin, el historiador de la literatura no concibe la modificación de otra forma que «progresivamente, por transición». Al legitimar biológicamente la variación estética, Taine y Brunetière activan la historia natural de tal manera que imponen a los fenómenos culturales una larga temporalidad y una restricción de continuidad. Tanto si las formas literarias se vinculan a un substrato vivo profundo, como si se postula una analogía de desarrollo, la ruptura franca, sin filiación, queda prohibida por aberrante.

Por ello Sully Prudhomme, a finales de siglo, encuentra en este enfoque biológico un argumento oponible al abandono del verso reglado. Heurística al principio, la comparación se convierte en polémica. El futuro premio Nobel escribe un «estudio sobre los fundamentos fisiológicos de la versificación», rematado por una «crítica de las tentativas de reformarla» ${ }^{1}$ (1904: 35). En él defiende el verso tradicional, en nombre de una historia de la poesía en la que «las reglas esenciales de la versificación son leyes fisiológicas, leyes de la naturaleza que se imponen a la palabra en el progreso secular de sus tentativas por convertirse en la más musical posible» (16). Dictadas por un «instinto del oído» (109), las formas, e incluso el empleo del verso, se desarrollaron en función de nuestra estructura corporal. Su uso evolucionaría para acompañar una transformación de nuestro organismo, que sólo podría intervenir de manera sumamente gradual:

Precisamente ese carácter fisiológico de las leyes fundamentales del verso tranquiliza y permite esperar, en un futuro más o menos próximo, el retorno de los rebeldes de buena fe a la disciplina de nuestro arte [...]. No es imposible que el organismo humano evolucione todavía, que el oído de los franceses se modifique, pero podemos afirmar que, si cambia, sus alteraciones no se realizarán de repente, sino que procederán con una lentitud extrema, imperceptibles durante siglos. Estemos pues seguros de que la naturaleza violentada recuperará sus derechos, como la gravedad, después de oscilaciones, conduce el péndulo a la posición vertical (17).

El paradigma historiográfico naturalista es tributario de una visión conservadora de la evolución literaria. Demasiado innovadores, los poetas responsables de la crisis del verso produjeron «una lengua híbrida» (16) que no hallará público, por no haber considerado las características de la especie humana actual. En esta aplicación a la creación literaria, el papel del modelo evolucionista, que, en biología, sirve para proyectar la naturaleza en la historia, se invierte. El modelo permite, si no santificar fuera de la historia el repertorio de prácticas estéticas, por lo menos enlentecer considerablemente la rapidez

\footnotetext{
${ }^{1}$ La obra recoge textos publicados durante los dos decenios anteriores.
} 
de una modificación tolerable. Esta situación parece dar la razón a Henri Meschonnic, para quien, en materia de teoría poética, «el fisiologismo deshistoriza tanto el cuerpo como el verso» (1982: 645). Sin embargo, como todo elemento tópico, las referencias a la fisiología eran susceptibles de articularse a otras tesis, y esa propia disciplina iba a evolucionar.

\section{¿Rimbaud premutante?}

Rimbaud, que figura entre los poetas en la mira de Sully Prudhomme, ya había relaciona do la estabilidad de las formas de expresión y la de la naturaleza humana - ello para elaborar, en una carta célebre $^{2}$, una reflexión sobre la posibilidad de una ruptura-.

En el modelo platónico y renaciente de la inspiración, el poeta, mens divinor, llega a alcanzar una palabra superior porque está poseído por una figura sobrehumana, que le arrastra más allá de sí mismo. Para Rimbaud, esta elevación tiene que resultar de una autopoética tal que el poeta se dirija sólo «hacia delante». Ya no se trata de alcanzar un don sino, «ladrón de fuego», de «hacerse vidente» —de «ir sin los dioses a la divinidad», dirá Valéry en su «Cantique des colonnes»-. Hijo de sus propias obras, el sujeto rimbaldiano puede (des)regular su «desarrollo natural» para orquestar su superación. Este deseo alcanza la historia literaria, de manera profética, ya que si tal ruptura se produjera, la fuerte herencia cultural de Taine se convertiría en cenizas. Al sujeto metamorfoseado le parecería posible y necesario «barrer esos millones de esqueletos que, desde un tiempo infinito, acumularon los productos de su tuerta inteligencia», ya que, para testimoniar sobre las «visiones» a las que su nuevo estado daría acceso, el creador rimbaldiano debería someter la lengua a una desregulación homóloga a la sufrida por su ser: «las invenciones de lo desconocido reclaman nuevas formas». Confrontado a ese mensaje, el resto de la humanidad podría entrever su propio futuro, de tal forma que un poeta, «multiplicador de progreso», guiaría a la comunidad humana hacia su futuro.

Ahora bien, Rimbaud hace de este salto un objetivo accesible. Presentándose como esa transformación, el poeta que imagina esa carta, «gran enfermo» y «gran Sabio», se sitúa simultáneamente en los dos extremos de un escalpelo: se remodela. La metamorfosis es tan orgánica como mental. En efecto, «se trata de hacer monstruosa el alma», pero Rimbaud precisa en seguida: « $i a$ la manera de los comprachicos, vaya! Imagínense un hombre que implanta y cría verrugas en su propia cara». Los comprachicos son estos bandidos que mutilan niños para crear fenómenos de feria, que Víctor Hugo acababa de escenificar, dos años antes, en L'Homme qui rit. Al hilo del pasaje de humor muy negro que les consagra, Hugo habla de una «producción artificial de casos teratológicos», o de «escultores en carne viva humana» (1869: 81-83). Mediante una «inefable tortura», Rimbaud propone pues al poeta operarse en vivo de su exceso de humanidad. Veinticinco años después, Wells y su Isla del doctor Moreau (1896), ese relato de experiencias de transformación de animales en hombres, asocia vivisección y modificación de la especie para forzar el propio desarrollo humano.

\footnotetext{
${ }^{2}$ A. Rimbaud, carta a Demeny del 15 de mayo de 1871 (1984: 201-205).
} 
Sully Prudhomme y Rimbaud difieren pues partiendo de premisas idénticas. Para el primero, hay que seguir la tradición, ya que no es posible situarse «de sopetón» más allá de lo humano. Para Rimbaud, el poeta debe romper con esa tradición, precisamente porque puede operar una revolución de su propia naturaleza. Las ciencias de la vida no le ofrecen en ese momento ningún ejemplo espontáneo oponible a las referencias de los conservadores, lo que explica la llamada a la vivisección (estrategia de perturbación voluntaria de la naturaleza) o al monstruo (anomalía del curso de las cosas). Pero Hugo de Vries aportará al debate literario ese modelo natural ausente al formular, en 1900 y en 1901, su Théorie de la mutation. Hasta entonces, el esquema evolucionista chocaba con dos atolladeros. Por una parte, ninguna prueba sostenía el postulado de la transmisión de los caracteres adquiridos por un individuo a su descendencia. Por otra parte, la paleontología ofrecía series discretas de especies fósiles, sin huellas de las formas intermedias involucradas en el modelo teórico. El holandés resuelve esas dificultades substituyendo los relatos de transformaciones lentas y seguidas por una historia natural hecha de transiciones repentinas y de aberraciones inciertas, en la cual el estatus de lo anómico evoluciona. «El objeto de mi obra es mostrar que las especies nacen mediante saltos bruscos, y que dichos saltos individuales son acontecimientos que pueden ser observados» (De Vries, 1901: I, VIII, traducción del autor): la novación natural entra así en el tiempo humano. En este nuevo modelo, «la nueva especie aparece de repente: sale de la especie pariente sin ninguna preparación visible, y sin que pueda observarse ninguna serie de formas transicionales» (I, 3). Con la insistente imagen del salto, recusación explícita del natura non facit saltus de Linneo, el concepto de mutación se impone como un acelerador histórico, o, si se retoma la fórmula de Rimbaud, como un «multiplicador de progreso». No se trata de postular aquí ninguna influencia entre esos dos autores, sino simplemente de identificar una similitud en la construcción de los dos relatos-modelo de novación. Mutatis mutandis, de Vries instala en la historia de la naturaleza un esquema historiográfico que ya era el del poeta, y ese paralelismo da lugar a una figura de torsión: la referencia argumentativa a lo vivo, activada por los partidarios de una estética conservadora, o moderadora, puede, a partir de ese momento, ser utilizada en su contra por los defensores de un «progreso» más drástico.

\section{La mutación como modelo formal}

Cuando Apollinaire, en 1918, teoriza el espíritu nuevo («L'esprit nouveau et les poètes»), enlaza con la postura rimbaldiana: «el poeta, por la naturaleza de sus exploraciones, está aislado en el nuevo mundo, donde entra él primero» (1991: 951). No obstante, ese aislamiento es muy relativo, puesto que, según Apollinaire, la biología explora simultáneamente, con otras ciencias, ese nuevo mundo. «Existen, escribe, miles de combinaciones naturales que nunca han sido compuestas. [Los sabios] las imaginan y las dirigen, componiendo así con la naturaleza este arte supremo que es la vida. Son esas nuevas combinaciones, esas nuevas obras del arte de la vida lo que llamamos progreso» (949). Para Apollinaire, los científicos aportan pues una prueba de la posibilidad de operar profundas rupturas históricas y, al modificar el propio ser vivo, relanzan la creación (visión demiúrgica, alimentada, desde 
los años 1910, por las investigaciones de Alexis Carrel sobre el cultivo de tejidos orgánicos). De ser referente o medida, la naturaleza se convierte en la materia de una poesis, que Apollinaire presenta como una completa obra artística: «los juegos divinos de la vida y de la imaginación dan rienda suelta a una actividad poética completamente nueva» (950) y se invita a los poetas a imaginar las fábulas que los científicos realizarán. Este sueño de emulación y de colaboración entre creadores de vida y de textos hallará alimento en los trabajos del biólogo Hermann Muller, quien obtiene en las moscas, en 1927, las primeras mutaciones artificiales. Al dotarse de «la posibilidad de introducir fracturas en los cromosomas» (Muller: 1962: 332; traducción del autor) ${ }^{3}$, la genética molecular gana a la vez un instrumento de observación (las mutaciones permiten establecer las primeras cartografías cromosómicas) y un instrumento de intervención. El hombre, al descifrar uno de los secretos de la naturaleza, parece condenado a fabricar nuevas criaturas, o bien a orquestar su propia mutación, y no escapó en absoluto a ciertos escritores, de la estirpe de Apollinaire, que estas ventajas científicas, fundadas en una «fractura» a la vez molecular y genética, permitían justificar una estrategia estética de ruptura.

Transition constituye un ejemplo contundente de ello. Fundada en 1927, esta revista plurilingüe, editada en París por Eugene Jolas, publica a autores como Gertrude Stein o James Joyce -escritores que algunos críticos acusan precisamente de fracturar la lengua ${ }^{4}$ - Para justificar su iconoclastia, Jolas consagra en 1935 un amplio dosier a las «patologías» del lenguaje y al «laboratorio de las palabras», ocasión para formular explícitamente un acercamiento ente escritura y biología, ya sugerido en diversas entregas anteriores. Jolas explica que el lenguaje «burgués», incapaz de dar cuenta de las evoluciones sociales acaecidas en la existencia de los hombres, está enfermo y en decadencia, e invita a orquestar su transformación para «apresurar la reintegración de la personalidad humana», vía una «readaptación de las palabras existentes», o por la «creación revolucionaria de palabras nuevas» (Jolas, ed., 1935: 144; traducción del autor) ${ }^{5}$. Pero también habla de una «transmutación metantropológica», una modificación de la especie humana que, apelando a la elaboración de un verbo nuevo, plantearía «el problema de la transmutación del lenguaje» (1935: 107) . En un momento en que los términos de mutación y transmutación se emplean indiferentemente en las ciencias de la vida, el dossier de Transition presenta así un ejemplo precoz de juego entre un uso literal y un empleo figurado (sociológico y estético) del concepto. A una humanidad que se modifica debe corresponderle una literatura igualmente plástica. Para ello, la mutación biológica, captada a la vez como fenómeno natural y como práctica aureolada de novedad, ofrece un modelo formal a la escritura. La revista multiplica las analogías entre ciertas prácticas textuales y los fenómenos de reordenamiento que los sabios describen y suscitan: al reconocer en la mutación un proceso de «fragmentación», «inversión»,

\footnotetext{
${ }^{3}$ H. J. Muller y A. Prokofjeva, «Continuity and Discontinuity of the Hereditary Material», en Comptes rendus de l'Académie des sciences de l'URSS, IV, 1-2 (1934), pp. 74-83.

${ }^{4}$ W. Carlos Williams defiende el «broken language» de Finnegans Wake en el número 8 de la revista (noviembre de 1927, p. 150).

${ }^{5}$ E. Jolas, «Inquiring about the Malady of Language».

${ }^{6}$ E. Jolas, «Transmutation Vertigraliste».
} 
«desaparición»o «translocación» de elementos ordenados linealmente ${ }^{7}$, Muller ofrece a los autores que desorganizan la sintaxis o que multiplican las palabras comodín una garantía metodológica y una figura heroica. Es posible, como la naturaleza o el sabio, concentrarse en las propias unidades del código. Como Muller, Jolas en su «laboratorio» realiza «experiencias de mutación lingüística» ${ }^{8}$, en las cuales fragmentos rotos de la lengua sufren recombinaciones. A partir de un poema saturado de neologismos, juega con su nombre para introducir explícitamente la referencia genética: «Take the old Uncle Gene and clasproll him into the eugenicon!» - Toma al viejo Tío Gen y enlaza-agítalo en el eugenicon! ${ }^{9}$ (Jolas, ed., 1935: 184)—. El escritor se convierte así en creador por desregulación, de modo que asistimos, si no a un eugenismo verbal, por lo menos al nacimiento de mutantes léxicos.

En el mismo número, Gottfried Benn critica la empresa de Jolas, invitando a respetar «la metamorfosis orgánica, regular, de las palabras» (Jolas, ed., 1935: 145). Y Camille Schuwer, para quien ningún idioma radicalmente innovador podrá destronar el uso, restablece la imagen del monstruo:

Por la mañana, cuando salgan del horno, crujientes y dorados al punto, y cubiertos de azúcar, contemplaréis largamente vuestros animales anfibios, de pie sobre sus patas traseras, combinando en sus células híbridas uñas, talón, mandíbula, antena, saliva y mucosidad ¡Ave!

Pero estaréis sin fuerza. Todos esos monstruos os aburrirán.

Porque son demasiado nuevos y brillantes (Jolas, ed., 1935: 166-167).

Como en la biología contemporánea ${ }^{10}$, el debate sobre el ritmo y la continuidad de la historia literaria está lejos de resolverse por el recurso al concepto de mutación, cuya ambivalencia muestra Schuwer: el poeta constructor de mutantes se muda en inquietante teraturgo o forja, salto inútil, criaturas de lengua inviables. Ello no impide que la mutación, concebida como una ruptura brusca con un pasado, una respuesta al presente y una irrupción de futuro, ofrezca la misma estructura temporal que la noción de vanguardia. En Jolas como en Rimbaud, la ruptura estética es a la vez mutante, puesto que está provocada por la evolución de la especie, y mutágenica, puesto que es capaz de provocar dicha evolución.

Las metáforas relativas a una escritura mutante han sido evocadas sin cesar desde entonces, siguiendo la evolución de las ciencias. En un ensayo reciente, Maurice Dantec propone someter la novela a una experiencia explícitamente imitada de las prácticas genéticas. El arte literario, «si algo queda de él, deberá emparentarse al del bioquímico molecular, que decodifica y junta los genes necesarios para la creación del Frankenstein terminal, en otros términos, debemos colocar la literatura, y el Mundo, sobre la mesa de disección, en el túnel de nuestro acelerador de partículas, y experimentar sin esperar, empezando por observar con atención los estragos así producidos» (2003a: 112). El autor justifica esta empresa mediante una historia literaria evolucionista y prospectiva: «para que una forma viva, es preciso que se desarrolle, es preciso pues que se adelante. [...] Quisiéramos substituir todas

${ }^{7}$ H. J. Muller, «Artificial Transmutation of the Genes», Science, 22 de julio de 1927 (Muller, 1962: 245-251; traducción del autor).

${ }^{8}$ Título de una sección de Transition incluida en el dosier «Laboratory of the Word» (Jolas, ed., 1935: 143-195).

${ }^{9}$ E. Jolas, «Old Century Pt. 27 Takes a Vacation (Essay in a Neo-American Language)».

${ }^{10}$ Sobre las discusiones que opusieron neodarvinianos y «saltacionistas» al hilo del siglo, véase Schmitt (2006). 
las formas de clonación degenerativa e inconfesada por una mutación determinista» (115). Como en los ejemplos precedentes, se trata de hacer mutar los textos de manera que la nueva literatura pueda a su vez «ser por sí misma un factor de mutación» (119). No obstante, Dantec rechaza, no sin coherencia, la etiqueta de vanguardia. La mutación, brusca solución de continuidad, no puede anunciarse. «Se trata de elaborar una GENÉTICA específica, y por ello no somos, no podemos ser una vanguardia» (120) -no por timidez en la ruptura, sino al contrario porque su propia radicalidad coloca el texto «transmutado» a la espera de lectores, de manera que la escritura mutante, «puro porvenir» (120) prueba su diferencia por la resistencia que opone a la asimilación, en el momento de su apariciónÉsta es por lo menos una de las aproximaciones posibles a Villa Vortex, gruesa novela o antinovela de 2003, que mimetiza en su estructura el movimiento de mutación descrito por Dantec. Un primer relato, policíaco, en efecto se interrumpe, después de varios centenares de páginas, para dar lugar a un segundo texto de relaciones inciertas con la primera narración, algunos de cuyos elementos reaparecen en gran desorden. Ahora bien, Dantec compara a menudo el código genético con una novela: «novela de nuestra vida biológica, [el $\mathrm{ADN}$ ] está compuesto por tres mil millones de signos, con un alfabeto de cuatro letras, que forman alrededor de cien mil párrafos o capítulos», de manera que cada uno de esos párrafos constituye «un gen, que codifica la historia de una proteína necesaria para cierta función en cierto órgano» (2003a: 132). En Villa Vortex, diversos pasajes invitan a observar recíprocamente la obra de ficción como la aplicación al primer relato de una mutación cuyas consecuencias se leerían en la segunda parte, desdoblándose así el libro «en una relación de transcriptasa inversa» (2003b: 386). Así, se entera uno de que «algo ha ocurrido en el continuum del relato, un calado de discontinuidades en el que cada una de ellas es eslabón de una cadena genética encriptada» (648), o incluso de que «las informaciones remontan la cadena del tiempo, como ciertas secuencias mutables se desplazan a lo largo de la cadena genética» (793). Pero el resultado de estas recombinaciones queda fuera del libro: sólo se habrá asistido a la «ontogénesis del relato» (804) durante su formación, y el fracaso aparente de la novela - compendio bastante indigesto - se convierte, según la génesis que se plantea, en la garantía paradójica de su capacidad de romper con nuestros usos y de presentarse «como una coextensión de la biología, como una topología dinámica y caótica» (2003a: 116).

Jolas y Dantec apelan así al modelo de la mutación para justificar y modelizar experiencias de escritura que amenazan la legibilidad y desregularizan los códigos genéricos y del lenguaje. Lejos de la imagen tradicional de orden asociado a la imitación de la naturaleza, la mutación ofrece un ejemple paroxístico del «bricolaje» actualizado, en el centro del programa biológico, por la genética contemporánea.

\section{La mutación como práctica}

La analogía entre gen y texto, sobre la cual reposan estos discursos, no ha cesado de inquietar a los especialistas de la vida y del lenguaje. En 1970, Roman Jakobson, por ejemplo, estima «legítimo preguntarse si el isomorfismo de esos dos códigos diferentes, genético y verbal, se explica por una 
simple convergencia debida a necesidades similares, o si los fundamentos de las estructuras lingüísticas manifiestas, chapadas sobre la comunicación molecular, no estarían directamente modeladas sobre los principios estructurales de ésta» (1970: 55). Pero François Jacob subraya los límites de esta asociación: un modelo no es la descripción de lo real, y «nadie ha escrito jamás el famoso mensaje de la herencia, trasmitido de una generación a otra» (1974: 200). No obstante, el uso de metáforas lingüísticas en biología ha facilitado ciertamente el empleo, a la recíproca, de comparaciones biológicas en literatura. Más aún: ha incitado a entender literalmente dichas figuras y a intentar emplear las biotécnicas para «redactar», con finalidades artísticas, un texto vivo —un programa adoptado por el poeta y artista plástico brasileño Eduardo Kac-

En la línea de las vanguardias que basaron su modernidad en la adaptación de nuevos vectores, Kac propone «utilizar las biotecnologías y los organismos vivos en poesía como un nuevo ámbito de creación verbal». Su manifiesto de 2003, Biopoetry, establece una lista de una veintena de realizaciones posibles. Así, considera una «escriptogénesis», la creación de un «ser completamente nuevo», o también una «poesía transgénica», consistente en traducir enunciados humanos a un código de cuatro caracteres, parecido al de los genes, sintetizar las moléculas del ADN correspondientes, incorporarlas en el genoma de criaturas vivas y finalmente estudiar las variaciones al hilo de las generaciones «por mutación, pérdida o cambio natural del $\mathrm{ADN}$ », retraduciendo en lenguaje humano la sección correspondiente a ese «transpoema» (Kac, 2003; traducción del autor). Por absurdo que parezca, este proyecto no es ninguna broma. Kac describe a posteriori las operaciones que realizó. En Genesis (1999), un versículo de la Biblia fue objeto de la traducción mencionada, para ser integrado al ADN de una bacteria, cultivada después en condiciones favorables a la mutación, de manera que el verbo sagrado, lejos de ser protegido en ese archivo de la carne, sufrió modificaciones que permitieron al poeta presentar las bacterias como coenunciadoras de la obra. El modelo de la mutación se transformó así en un programa práctico, y Genesis, realizado con la colaboración de científicos, se hace directamente eco de las reflexiones de Apollinaire respecto de una posible poética de lo vivo. Parecería que el desarrollo combinado de la analogía entre códigos genéticos y texto hubiera acarreado finalmente la aparición de una figura de poeta-genetista, que durante mucho tiempo fue la obsesión del discurso crítico, sobre todo en Diderot, quien indicaba ya, en Le Rêve de d'Alembert, que «el arte de crear seres que no lo son, imitando a los que son, [sería] la verdadera poesía» (1769: 404). Último avatar de estos intercambios entre literatura y biología, la biopoesía expone las transformaciones de que es objeto hoy lo vivo, cada vez más maleable, al mismo tiempo que somete la propia poesía a una forma de fusión con un nuevo medio, perturbador de las compartimentaciones de las disciplinas ${ }^{11}$.

La mutación biológica pudo funcionar como un modelo para ciertas vanguardias al ofrecer un ejemplo natural de ruptura al servicio de argumentos de la novación. Ese emplazamiento permitió un cambio importante en el uso crítico del topos de la imitación de lo vivo, al término de un diálogo que muestra que la historia literaria, todavía hoy, no se construye sin considerar los otros tipos de relatos

${ }^{11}$ Para un análisis más detallado de Genesis y del recorrido de Kac, de la poesía concreta al arte biotec, véase Marchal (2005). 
históricos. Tal vez ello permite también iluminar nuestra fascinación por el fenómeno genético, descubriéndole resonancias en la lógica de superación estética que habrá estructurado la modernidad. $\mathrm{Si}$, según McLuhan, «toda nueva tecnología es una mutación evolutiva biológica que abre nuevas puertas a la percepción del hombre y nuevos ámbitos para su acción» (1997: 282, traducción del autor), la humanidad del siglo XX no sólo habrá descubierto que podía, por sus nuevos saberes, destruir el mundo, sino también que podría probablemente orquestar su propia caducidad biológica. Apropiarse del modelo mutante para articular un discurso literario constituye a la vez una forma de tranquilizarse, o bien de soñarse como demiurgo, y una manera de enunciar una angustia. Hacer del genetista el poeta de las especies futuras es además pedirle que dé cuenta, no sólo de la ética, sino también de la estética del mundo del cual él será autor ${ }^{12}$.

Traducción de Joel Estopà

\section{Bibliografía}

Apollinaire, G. (1991): Oeuvres en prose complètes. Eds. P. Caizergues y M. Décaudin, París, Gallimard, t. II.

BRUnetiere, F. (1890): Évolution des genres dans l'histoire de la littérature. París. Hachette, 1910.

Dantec, M. (2003a): Péripheriques, París, Seuil.

- (2003b): Villa Vortex, París, Gallimard.

DE VRIES, H. (1901): The Mutation Theory: Experiments and Observations on the Origin of Species in the Vegetable Kingdom. Trad. J. Famer y A. Derbishire. Londres, Kegans, 1910-1911.

Diderot, D. (1769): Le Rêve de d'Alembert, en M. Delon, ed., Euvres philosophiques. París, Gallimard, 2010, pp. 343-409.

Hugo, V. (1869): L'Homme qui rit. París, Gallimard, 2002.

JACOB, F. (1974): «Le modèle linguistique en biologie», Critique, 322, pp. 197-205.

JAKOBSON, R. (1970): «Relations entre la science du langage et les autres sciences», en Essais de linguistique générale. París, Minuit, 1973, vol. II, pp. 9-76.

JoLAS, E. ed. (1935): Transition, $\mathrm{n}^{\mathrm{o}} 23$.

KAC, E. (2003): Biopoetry, en www.ekac.org/biopoetry.html (última consulta, 30-11-2015).

Marchal, H. (2005): «L'huissier de la maison de l'homme», en E. Rossi, ed., Eduardo Kac: Move 36. París, Filigranes, pp. 19-23.

McLuhan, E., y Zingrone, F., eds. (1997): Essential McLuhan. Londres, Routledge.

Meschonnic, H. (1982): Critique du rythme. Lagrasse, Verdier.

Muller, H. J. (1962): Studies in Genetics. Bloomington, Indiana University Press.

Rimbaud, A. (1984): Poésies. D. Leuwers, ed. París, Le Livre de Poche.

SCHMitT, S. (2006): «Monstres et mutants prometteurs», Critique, 709-710, pp. 493-503.

${ }^{12}$ Este artículo ha sido publicado con el título «Mutation biologique et avant-gardes littéraires», en la revista Critique, 709 710 (junio-julio 2006), pp. 566-579. Se reproduce en traducción con autorización de Éditions de Minuit. 
92 Tropelías. Revista de Teoría de la Literatura y Literatura Comparada, 25 (2016) Hugues Marchal

Sully Prudhomme (1904): Testament poétique, en Oeuvres. París, Lemerre, t. VI.

TAINE, H. (1866): Histoire de la littérature anglaise. París, Hachette, $2^{\mathrm{a}}$ ed. revisada, t. I. (1867): De l'idéal dans l'art. París, Germer-Baillère.

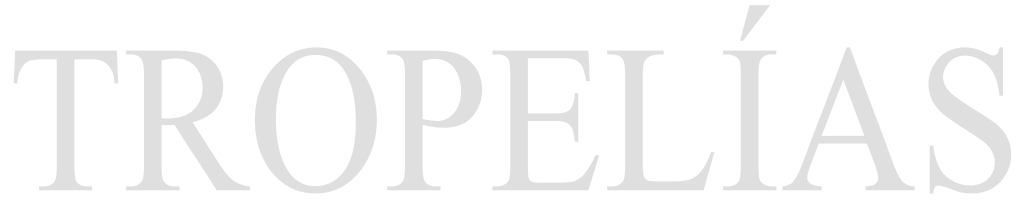

